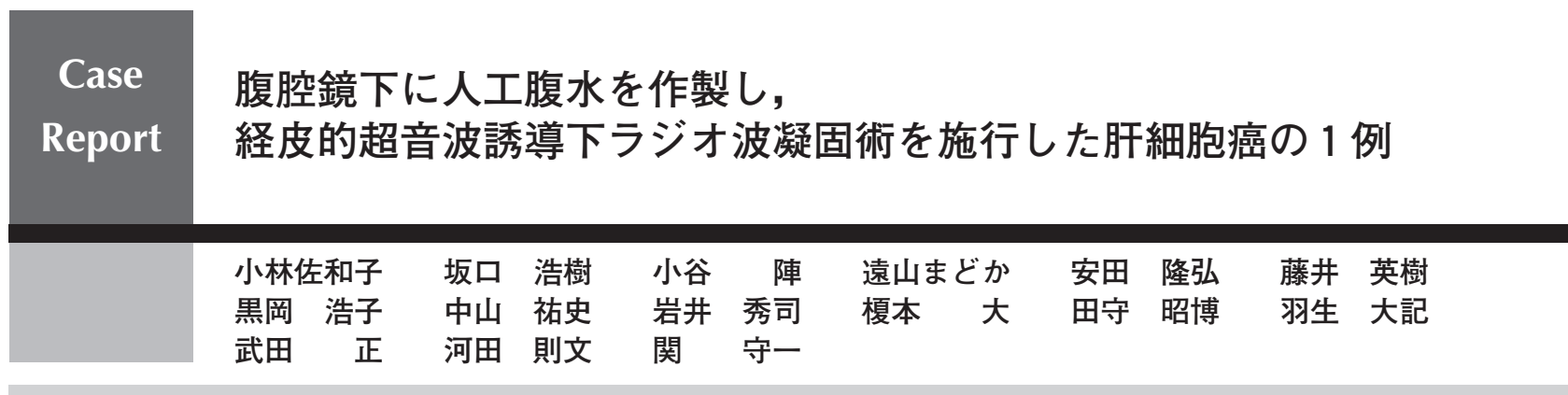

\title{
A case of hepatocellular carcinoma successfully treated by percutaneous radiofrequency ablation using the laparoscopic artificial ascites technique
}

\begin{abstract}
Sawako Kobayashi, Hiroki Sakaguchi, Jin Kotani, Madoka Toyama, Takahiro Yasuda, Hideki Fujii, Hiroko Kurooka, Yuji Nakayama, Shuji Iwai, Masaru Enomoto, Akihiro Tamori, Daiki Habu, Tadashi Takeda, Norifumi Kawada and Shuichi Seki
\end{abstract}

\begin{abstract}
A 70-year-old man was admitted for suspected hepatocellular carcinoma (HCC). Abdominal CT detected a tumor mass $2.5 \mathrm{~cm}$ in diameter protruding from the surface of the right lobe of his liver. We decided to perform radiofrequency ablation (RFA) with laparoscopic guidance. Laparoscopy revealed the HCC being adjacent to the costae on the outermost side of the right lobe; it was difficult to safely puncture an electrode needle into the tumor. Hence, we infused normal saline (artificial ascites) into the space between the liver and abdominal wall, and then performed percutaneous RFA with ultrasonography guidance. Using this laparoscopic artificial ascites technique, we could safely and easily perform ultrasonography-guided percutaneous RFA for HCC on the outermost side of the right lobe of the liver, which is otherwise difficult to treat by laparoscopic or percutaneous approach.
\end{abstract}

Key words : hepatocellular carcinoma, radiofrequency ablation, artificial ascites, laparoscope

Accepted on Dec. 14, 2006

\section{大阪市立大学大学院医学研究科肝胆膵病態内科学 干 545-8585 大阪府大阪市阿倍野区旭町 1-4-3}

Department of Hepatology, Graduate School of Medicine, Osaka City University

Address : 1-4-3 Asahimachi, Abeno-ku, Osaka-city, Osaka, 545-8585, Japan 
緒 言

肝細胞癌 (HCC) に対する内科的局所治療として, 経皮的治療及び腹腔鏡的治療がある. 腹腔鏡的治療は直 視下で治療し得る点で経皮的治療に比べて効果が確実で ある。特に，経皮的治療が困難な表在性，あるいは横隔 膜直下腹側の HCCに対して腹腔鏡的治療はよい適応と なる。そのため, 当科では腹腔鏡的治療が施行可能な HCCに対し，1995年より積極的に腹腔鏡的治療を施行 してきた. しかし, 深在性のものや横隔膜直下背側のも のに対しては施行困難であるため, 経皮的治療を施行す ることが多い。このように，当科では腫瘍の大きさや局 在に応じて最適と考えられる治療法を選択している.

今回我々は, 治療が困難な肝右葉最外側肝表面の HCCに対して, 腹腔鏡下に人工腹水を作製し, 経皮的 に超音波誘導下ラジオ波凝固術（RFA）を施行した 1 例を経験したので報告する。

\section{I. 症例}

70 歳, 男性.

主 訴：特になし.

既往歴：33歳時に外傷にて膀胱・尿道裂傷, 骨盤骨 折あり.その際に輸血を受けている.

家族歴：特記すべきことなし.

現病歴：1993年（57歳時), 近医にてC 型慢性肝炎を
指摘され，当科紹介受診. 1995年（59歳時）にはイン ターフェロン療法を受けたが, ウイルスは消失しなかっ た.その後, 当科外来に定期的に通院中であったが, 2006 年 3 月（70歳時）に肝 $S_{5}$ 表面に長径 $25 \mathrm{~mm}$ 大の腫 瘍を指摘されたため, 精查加療目的で入院となった.

入院時現症：身長 $157.8 \mathrm{~cm}$, 体重 $61.25 \mathrm{~kg}$, 体温 $36.9{ }^{\circ} \mathrm{C}$, 血圧 $133 / 70 \mathrm{mmHg}$, 脈拍 $72 /$ 分 (整, 左右差 なし), 意識清明, 貧血・黄疸なし, 腹部平坦軟, 腫瘤 触知せず，腹水・浮腫なし.

入院時血液検査 : 貧血, 血小板減少, 低アルブミン血 症, 肝胆道系酵素の上昇, 腫瘍マーカー ( A F P , PIVKA II）の上昇が認められた（表 1 ）.

入院時腹部ダイナミック CT : 肝 $\mathrm{S}_{5}$ 表面に突出する長

\section{表 1 入院時血液検查}

\begin{tabular}{|c|c|c|c|}
\hline WBC & $5,800 / \mathrm{mm}^{3}$ & LDH & 496IU/L \\
\hline RBC & $331 \times 10^{4} / \mathrm{mm}^{3}$ & CK & $105 \mathrm{IU} / \mathrm{L}$ \\
\hline $\mathrm{Hb}$ & $11.9 \mathrm{~g} / \mathrm{dL}$ & BUN & $13 \mathrm{mg} / \mathrm{dL}$ \\
\hline $\mathrm{Ht}$ & $34.6 \%$ & Cre & $0.57 \mathrm{mg} / \mathrm{dL}$ \\
\hline Plt & $7.1 \times 10^{4} / \mathrm{mm}^{3}$ & FBS & $110 \mathrm{mg} / \mathrm{dL}$ \\
\hline PT & $72 \%$ & T-Cho & $220 \mathrm{mg} / \mathrm{dL}$ \\
\hline TP & $6.8 \mathrm{~g} / \mathrm{dL}$ & $\mathrm{TG}$ & $146 \mathrm{mg} / \mathrm{dL}$ \\
\hline Alb & $2.7 \mathrm{~g} / \mathrm{dL}$ & CRP & $0.18 \mathrm{mg} / \mathrm{dL}$ \\
\hline T-Bil & $2.4 \mathrm{mg} / \mathrm{dL}$ & & \\
\hline D-Bil & $1.3 \mathrm{mg} / \mathrm{dL}$ & HBsAg & - \\
\hline AST & 83IU/L & $\mathrm{HBsAb}$ & - \\
\hline ALT & 46IU/L & $\mathrm{HCV}-\mathrm{Ab}$ & + \\
\hline ALP & 338IU/L & & \\
\hline $\mathrm{CHE}$ & 61IU/L & AFP & $51.3 \mathrm{ng} / \mathrm{mL}$ \\
\hline$\gamma-$ GTP & 58IU/L & PIVKA II & $262 \mathrm{mAU} / \mathrm{mL}$ \\
\hline LAP & 80IU/L & & \\
\hline
\end{tabular}
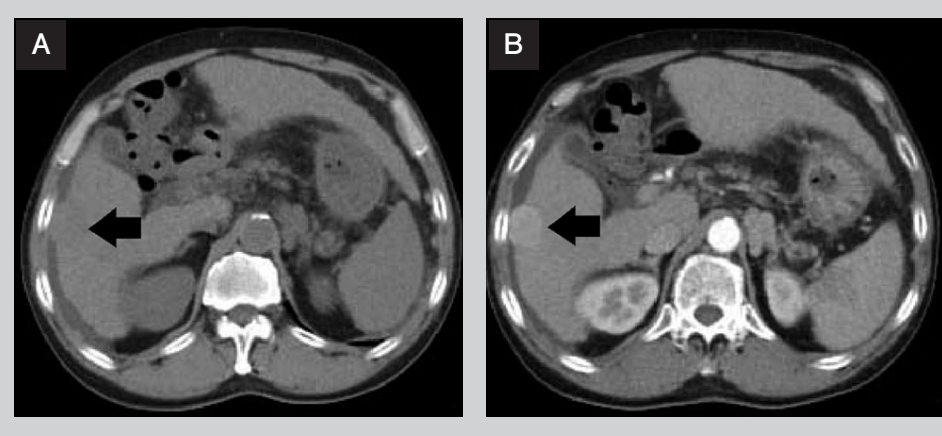

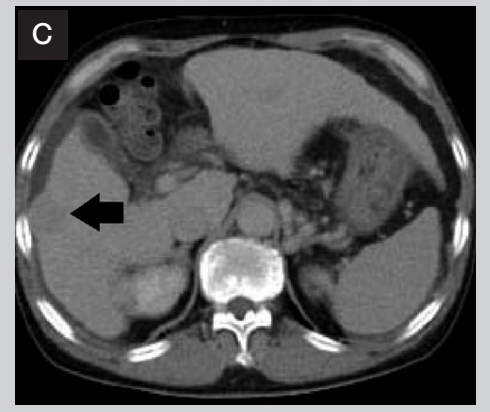

図 1 術前腹部ダイナミック CT

A : plain, B : early, C : late

肝 $\mathrm{S}_{5}$ 表面に突出する長径 $25 \mathrm{~mm}$ 大の肝内占拠性病変 (space occupying lesion：SOL) を認める.同部は early enhancementを受け, lateでwashoutされる (矢印). 
径 $25 \mathrm{~mm}$ の腫瘍を認めた。同部は造影早期相で濃染され, 後期相でwash outされていた（図 1 ).

腹部超音波検査：肝 $\mathrm{S}_{5}$ 表面に突出する $25 \times 19 \mathrm{~mm}$ 大 の腫瘍を認め，カラードプラでは周囲に血流を認めた.

以上より $\mathrm{HCC}$ と診断し，腫瘍は肝 $\mathrm{S}_{5}$ 肝表面に突出し て存在していたため，治療として腹腔鏡下 RFA を選択 した。

左下腹部より気腹後，腹腔鏡を挿入して観察したとこ ろ，肝は赤褐色調であり，表面は結節状であった。腫瘍 は右葉最外側にあり，胁骨に近接して存在していた。右 肋弓下より径 $1 \mathrm{~cm}$ のトロッカーを挿入し，超音波腹腔 鏡下にCool-tip ${ }^{\circledR}$ 針の穿刺を試みるも，腫瘍及び肝表面に 対して接線方向での穿刺になるため，安全に穿刺・治療 することは困難であった。そのため，同部より肝右葉表 面に約 $200 \mathrm{~mL}$ の生理食塩水を注入して人工腹水を作製 し，その上で経皮的に超音波誘導下 RFA を施行した (図 2 ).

術後少量の右胸水を認めたが，その他に大きな合併症 はなく経過し，術後腹部ダイナミックCTによっても治
療効果は良好であった（図３）。

\section{II. 考察}

HCCに対するRFA は1999年に我が国に導入されて以 来，HCCに対する局所療法として普及している。エ夕 ノール注入療法やマイクロ波凝固療法に比べると, 1 回 での治療範囲が大きいことや，確実に径 2 〜 $3 \mathrm{~cm}$ の壊 死範囲を得ることができるなど優れている点が多く，ま た太い脈管を温存することができるため，肝梗塞をはじ めとする脈管障害に起因する合併症も少ないと言われて いる.しかしながら, 肝表面や多臓器に隣接した部位に ある HCCに対しては，熱エネルギーが周囲に影響して， 横隔膜，腹壁や他臓器に熱傷を引き起こす危険がある ${ }^{12}{ }^{2}$. 腹腔鏡下 RFA は, 直視下で横隔膜, 腹壁や近隣臓器 をある程度遊離して治療できるため, 肝表面の HCCに 対してはよい適応となる ${ }^{3)}$. そのため，2000年より我々 の施設でも, 可能な症例に対しては積極的に腹腔鏡下 RFA を施行してきた ${ }^{4)}$. しかしながら，肝右葉最外側
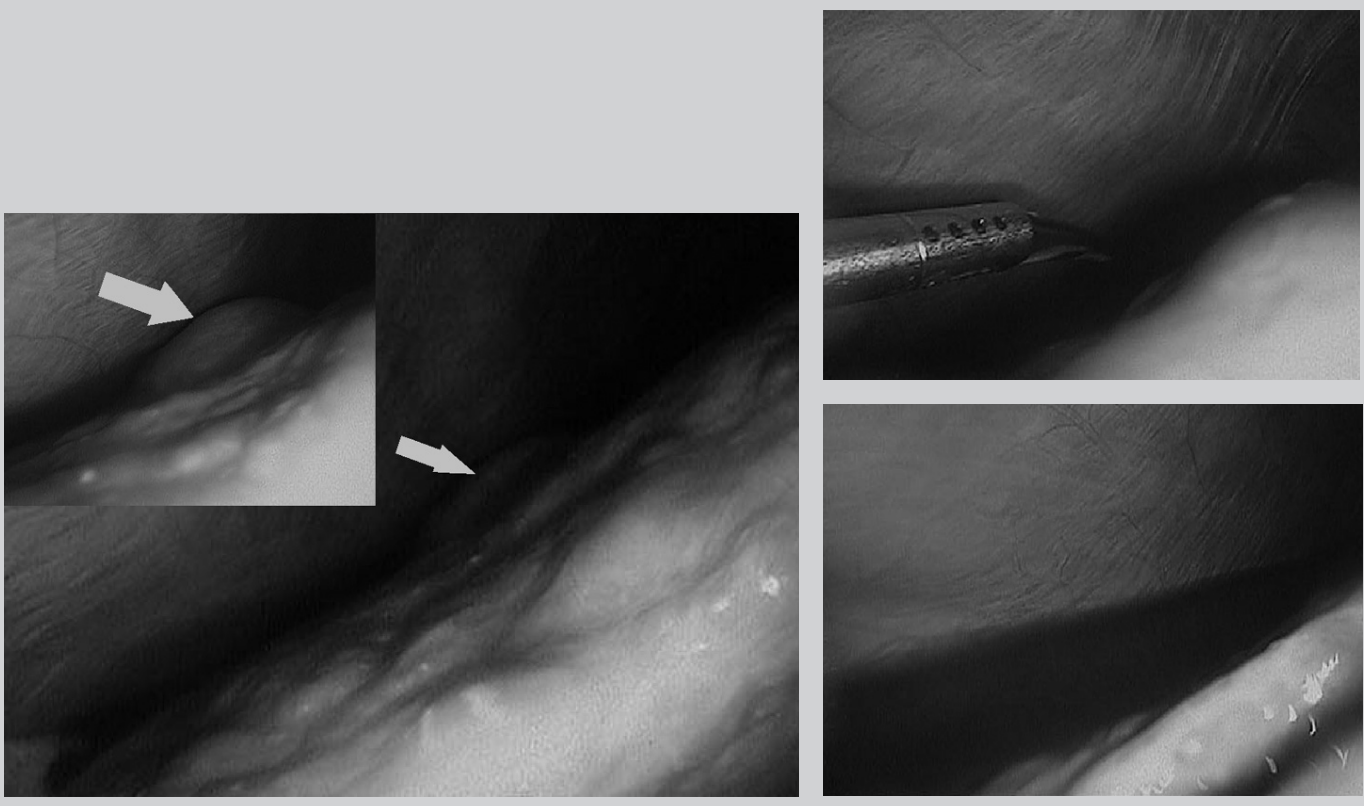

図 2 腹腔鏡像

腫瘍は右葉最外側にあり，肋骨に近接して存在していた（矢印）。右肋弓下ょり肝右葉表面に約 $200 \mathrm{~mL}$ の生理食塩水を注入して人 工腹水を作製し，その上で経皮的に超音波誘導下RFAを施行した。 

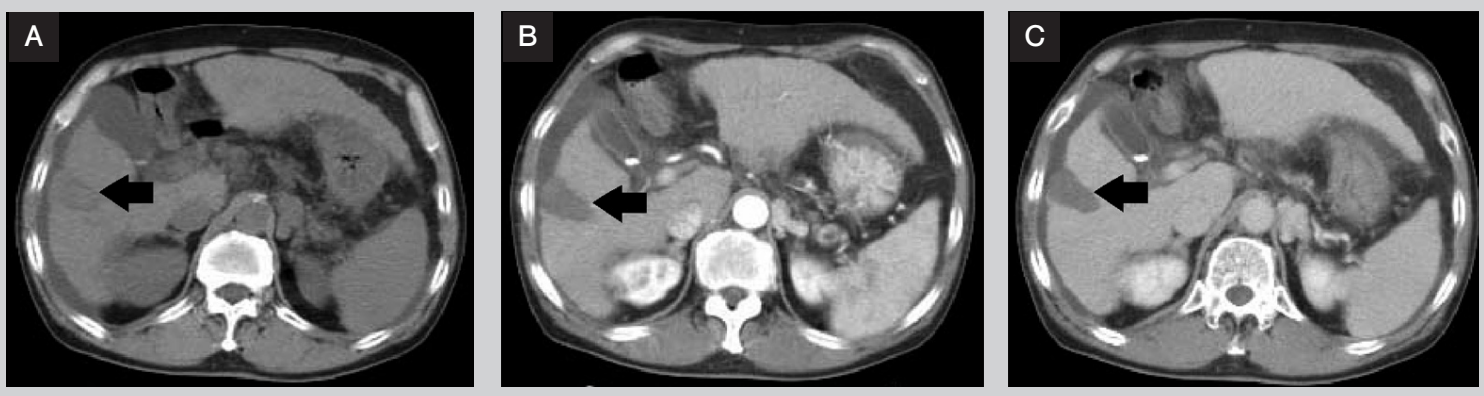

図 3 術後腹部ダイナミック CT

A : plain, B : early, C : late

治療部はlow density area化している (矢印).

表面の HCC は，腹腔鏡的治療では右肋弓下からの電極 針穿刺は接線方向となるため困難である．また，肋間か らの穿刺では気胸を引き起こす可能性が高く，安全な治 療が困難である。経皮的にRFA 治療を行うとすれば, 熱傷の危険を回避するために人工腹水の作製が必要であ る．腹壁あるいは横隔膜と肝の間に液体が貯留すること により熱が伝導しなくなり，また液体の冷却作用も加わ って，腹壁や横隔膜に熱が及ぶことを防止できる ${ }^{5)}$.し かしながら，ブラインドで目的とする位置に人工腹水を 作製するのは困難であり，また癒着がある時には危険な 場合もある。

今回我々は，腹腔鏡下に人工腹水を作製したところ， 少量の生理食塩水注入で目的とする位置に確実に人工腹 水を作製でき，安全に経皮的超音波誘導下 RFA を施行
することができた，治療効果も良好で，術後 7 力月経過 しているが現在のところ再発はない.

腹腔鏡的及び経皮的治療が困難な肝右葉最外側の HCCに対しては，腹腔鏡的に人工腹水を作製し，経皮 的に超音波誘導下治療を行うという，両方を組み合わせ た治療法が有効であると考えられた。

\section{結 語}

腹腔鏡的あるいは経皮的治療が困難な HCCに対して, 両方を組み合わせた治療法が有効であったＨCCの局 在や大きさに応じて，最適と考えられる治療法を選択す るのがよいと考えられる。

\section{References}

1） 椎名秀一郎，寺谷卓馬，小尾俊太郎，佐藤新平，小池幸宏，段 佳之，赤松雅俊，藤島知則，吉田英雄，加藤直也，今井康雄，今村雅俊，浜村 啓介，白鳥康史，小俣政男：Cool-tip型電極を用いた経皮的ラジオ波焼灼療法による肝細胞癌の治療。肝臓 41：24-30，2000

2) Ikeda M, Okada S, Ueno H, Okusaka T, Kuriyama H : Radiofrequency ablation and percutaneous ethanol injection in patients with small hepatocellular carcinoma : a comparative study. Jpn J Clin Oncol 31 : 322-326, 2001

3 ) Seki S, Sakaguchi H, Kadoya H, Morikawa H, Habu D, Nishiguchi S, Shiomi S, Kitada T, Kuroki T : Laparoscopic microwave coagulation therapy for hepatocellular carcinoma. Endoscopy $32: 591-597,2000$

4 ）坂口浩樹，萩原淳司，遠山まどか，安田隆弘，藤井英樹，小林佐和子，中山祐史，岩井秀司，格谷洋和，榎本 大，田守昭博，羽生大記，武田 正，河田則文，関 守一：肝細胞癌における局所熱凝固療法の適応と成績. J Microwave Surg 24：87-89，2006

5 ）後藤 亨，小川真実，樹田康子，古谷 亮，森 一博：人工腹水注入併用により安全に経皮的ラジオ波焼灼療法が施行できた肝左葉先端の肝細 胞癌の 1 例. 肝臟 $44 ： 421-427,2003$ 